Part of Journal of Research of the National Bureau of Standards, Volume 27, September 1941

\title{
HEATS OF ISOMERIZATION OF THE FIVE HEXANES*
}

\author{
By Edward J. R. Prosen and Frederick D. Rossini
}

\section{ABSTRACT}

A procedure is outlined and utilized for determining with high precision the ratios of the heats of combustion, and hence the heats of isomerization, of the five hexanes. In principle, the ratio of the heats of combustion of any two isomers was determined as the inverse ratio of the masses of carbon dioxide whose formation in the combustion of the respective hexanes produced identical increases of temperature in the calorimeter system, measured as an increase in the resistance of the platinum resistance thermometer.

The following values were obtained for the liquid state at $25^{\circ} \mathrm{C}$, and calculated to the gaseous state at $25^{\circ} \mathrm{C}$ and $0^{\circ} \mathrm{K}$ :

\begin{tabular}{|c|c|c|c|}
\hline \multirow{3}{*}{ Isomer } & \multicolumn{3}{|c|}{$\begin{array}{l}\text { Heat of isomerization, } \Delta H \\
\quad \text { For } n-\mathrm{C}_{6} \mathrm{H}_{14}=i-\mathrm{C}_{6} \mathrm{H}_{14}\end{array}$} \\
\hline & \multirow{2}{*}{$\begin{array}{l}\text { Liquid } \\
25^{\circ} \mathrm{C}\end{array}$} & \multicolumn{2}{|c|}{ Gas } \\
\hline & & $25^{\circ} \mathrm{C}$ & $0^{\circ} \mathrm{K}$ \\
\hline $\begin{array}{l}n \text {-Hexane } \\
\text { 2-Methylpentane } \\
\text { 3-Methylpentane..... } \\
\text { 2, 3-Dimethylbutane... } \\
\text { 2, 2-Dimethylbutane... }\end{array}$ & $\begin{array}{l}\text { kcal/mole } \\
0 \\
-1.30 \pm 0.21 \\
-0.76 \pm 0.19 \\
-1.96 \pm 0.20 \\
-3.49 \pm 0.18\end{array}$ & $\begin{array}{l}\text { kcal/mole } \\
0 \\
-1.68 \pm 0.23 \\
-1.09 \pm 0.21 \\
-2.58 \pm 0.22 \\
-4.44 \pm 0.21\end{array}$ & $\begin{array}{l}\text { kcal/mole } \\
0 \\
-1.04 \pm 0.25 \\
-0.42 \pm 0.23 \\
-1.89 \pm 0.24 \\
-3.60 \pm 0.23\end{array}$ \\
\hline
\end{tabular}

Values for the heats of isomerization for the gaseous state at $600^{\circ}$ and $1,000^{\circ} \mathrm{K}$ were also calculated, utilizing values of $H^{\circ}-H_{0}^{\circ}$ calculated by Pitzer for each of the isomers at these temperatures.

\section{CONTENTS}

I. Introduction 290

II. Unit of energy, molecular weights, etc

III. Method and apparatus

1. Method

2. Apparatus _... 292

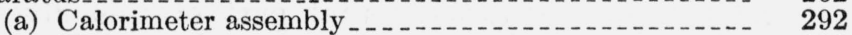

(b) Thermometric system

(c) Combustion bomb_..... 294

${ }^{*}$ Presented before the Division of Physical and Inorganic Chemistry at the meeting of the American Chemical Society at Atlantic City, N. J., September 8 to $12,1941$. 
IV. Chemical procedure

1. Preparation of the hexanes

2. Sealing of the hydrocarbons in glass ampoules.

3. Ignition of the hydrocarbon

4. Purification of the oxygen used for combustion

5. Examination of the products of combustion

6. Determination of the amount of reaction

V. Calorimetric procedure

1. Determination of the ignition energy 301

2. Combustion experiments _.. 302

3. Correction for the formation of nitric acid

VI. Results of the present investigation

VII. Data of previous investigations

VIII. Heats of isomerization as a function of the temperature

IX. Discussion

X. References

\section{INTRODUCTION}

In continuation of the program of determining the heats of formation and of isomerization of the paraffin hydrocarbons $[1,2,3],{ }^{1}$ calorimetric measurements have been made which yield values for the differences in the heats of combustion of the five hexanes in the liquid state of $25^{\circ} \mathrm{C}$. These values, which are also the heats of isomerization in the liquid state at $25^{\circ} \mathrm{C}$, have been combined with calculated values for the differences in the heats of vaporization to give values for the heats of isomerization in the gaseous state at $25^{\circ} \mathrm{C}$. Combination of these with values for the heat content of the various isomers in the gaseous state as a function of the temperature gives values for the heats of isomerization in the gaseous state at several temperatures from $0^{\circ}$ to $1,000^{\circ} \mathrm{K}$.

\section{UNIT OF ENERGY, MOLECULAR WEIGHTS, ETC.}

The unit of energy upon which the values reported in this paper are based is the international joule. For conversion to the conventional artificial, or defined, calorie, the following relation is used [4]:

$$
4.1833 \text { international joules }=1 \text { calorie. }
$$

The molecular weight of carbon dioxide, the mass of which was used to determine the amount of reaction, was taken as 44.010 , from the 1941 table of atomic weights [5].

The uncertainties assigned to the various quantities dealt with in this paper were derived, where possible, by a method previously described [6]. In other cases, reasonable estimates of the uncertainty were made.

\section{METHOD AND APPARATUS}

\section{METHOD}

The aim of the experimental part of this investigation was to determine as precisely as possible the values of the ratio of the heat of combustion of each isomer of hexane to that of normal hexane. The difference between unity and the value of this ratio, multiplied by an accepted value for the heat of combustion of normal hexane, gives the

\footnotetext{
${ }^{1}$ Figures in brackets indicate the literature references at the end of this paper.
} 
difference between the heat of combustion of normal hexane and the given isomer. In principle, the ratio of the heats of combustion of any two isomers was determined as the inverse ratio of the masses of carbon dioxide whose formation in the combustion of the respective hexanes produced identical increases of temperature in the calorimeter system, measured as an increase in the resistance of the platinum resistance thermometer. With this procedure, the energy equivalent of the calorimeter system need be known only approximately, and, in the limiting case where the calorimetric conditions are the same in all experiments for all of the isomers, the energy equivalent need not be known at all.

The method of reducing the experimental observations was as follows: Let

$\Delta R_{c}=$ the corrected increase in temperature of the calorimeter system, expressed as the increase in resistance in ohms of the given platinum resistance thermometer at a mean temperature of $26.50^{\circ} \mathrm{C}$, as measured with the given resistance bridge;

$E_{s}=$ the energy equivalent, over a "standard" interval of temperature, of the "standard" calorimeter system, obtained as the ratio of a given quantity of electric energy to the value of $\Delta R_{c}$ produced by it and expressed as international joules per ohm;

$E=$ the energy equivalent of the actual calorimeter system;

$\Delta r_{i}=$ the increase in temperature of the calorimeter system, expressed as the increase in resistance in ohms of the platinum thermometer, produced by the ignition process of heating and burning the iron wire;

$\Delta r_{n}=$ the increase in temperature of the calorimeter system, expressed as the increase in resistance in ohms of the platinum thermometer, produced by the formation of the small amount of nitric acid in the combustion;

$C=$ the heat capacity of the amount of hydrocarbon placed in the bomb, expressed as joules per ohm increase in resistance of the given platinum resistance thermometer;

$q=$ the heat evolved, in international joules per gram of carbon dioxide, in the combustion of the hydrocarbon in the bomb process, with the pressure of oxygen, the mass of hydrocarbon, and the mass of water placed in the bomb being sub. stantially the same in all experiments;

$m_{\mathrm{CO}_{2}}=$ the mass of carbon dioxide formed in the combustion of the hydrocarbon; and

$\delta=a$ very small correction term, expressed as joules per ohm increase in resistance of the given platinum resistance thermometer, to take account of (a) variations in the mass of the glass ampoule from the "standard" value of $0.20 \mathrm{~g}$, and (b) variations in the mean temperature of an experiment from the "standard" value of $26.50^{\circ} \mathrm{C}$.

The following relations hold:

$$
\begin{gathered}
E=E_{s}+C+\delta \\
q m_{\mathrm{CO}_{2}}=\left(\Delta R_{c}-\Delta r_{t}-\Delta r_{n}\right) E .
\end{gathered}
$$


Eliminating $E$ and solving for $q / E_{s}$, which will be called $B$, there is obtained

$$
B=\frac{q}{E_{s}}=\frac{\Delta R_{c}}{m_{\mathrm{Co}_{2}}}\left(1+\frac{C+\delta}{E_{s}}\right)\left(1-\frac{\Delta r_{i}+\Delta r_{n}}{\Delta R_{c}}\right) .
$$

The terms $(C+\delta) / E_{s}$ and $\left(\Delta r_{i}+\Delta r_{n}\right) / \Delta R_{c}$, which are each small in comparison with unity and have values near 0.00013 and 0.0014 , respectively, in all the combustion experiments for all the isomers, substantially cancel in obtaining the ratio of the value of $B$ for one isomer to that for another.

For any two isomers, the ratio of the heats evolved per gram of carbon dioxide is equal to the ratio of their heats of combustion per mole. If the subscripts $n$ and $i$ refer to the normal paraffin and the branched-chain isomer, respectively, and $-\Delta U_{B}$ is the heat evolved per mole of hydrocarbon on combustion in the bomb process, then

and

$$
\left(q / E_{s}\right)_{i} /\left(q / E_{s}\right)_{n}=B_{i} / B_{n}=\left(-\Delta U_{B}\right)_{i} /\left(-\Delta U_{B}\right)_{n}
$$

$$
\left(-\Delta U_{B}\right)_{n}-\left(-\Delta U_{B}\right)_{i}=\left(-\Delta U_{B}\right)_{n}\left(1-B_{i} / B_{n}\right) .
$$

For the reaction

$$
n-\mathrm{C}_{6} \mathrm{H}_{14}(\mathrm{liq})=i-\mathrm{C}_{6} \mathrm{H}_{14}(\mathrm{liq}),
$$

the energy of isomerization at the pressure in the bomb, $30 \mathrm{~atm}$, is

$$
\begin{gathered}
\left(U_{i}-U_{n}\right)(\mathrm{liq}, 30 \mathrm{~atm})=-\left[\left(-\Delta U_{B}\right)_{n}-\left(-\Delta U_{B}\right)_{i}\right] \\
=-\left(-\Delta U_{B}\right)_{n}\left(1-B_{i} / B_{n}\right) .
\end{gathered}
$$

That is, the energy of isomerization of the normal paraffin into the given isomer, for the liquid state at the pressure in the bomb, is equal to a constant, $\left(\Delta U_{B}\right)_{n}$, multiplied by the difference between unity and the experimentally determined value of the ratio $B_{i} / B_{n}$. Since the energy of isomerization lies in the range from 1 to $5 \mathrm{kcal} / \mathrm{mole}$, while the heat of combustion, $-\Delta U_{B}$, is near $1,000 \mathrm{kcal} / \mathrm{mole}$, the important advantage of this method of handling the experimental observations is that it retains all the possible precision in getting the energies of isomerization as differences in the heats of combustion, and, further, the absolute value of the heat of combustion of any one isomer need not be known at all accurately. For example, an uncertainty of $1 / 2$ percent in the value of $\left(-\Delta \dot{U}_{B}\right)_{n}$ does not significantly affect the value calculated for a given energy of isomerization. Since in the foregoing equations $B$ is essentially $\Delta R_{c} / m_{\mathrm{CO}_{2}}$, the important quantity to determine for each isomer is the quotient of the increase in resistance of the given platinum resistance thermometer divided by the corresponding mass of carbon dioxide formed.

\section{APPARATUS}

(a) CALORIMETER ASSEMBLY

With some changes, the calorimeter assembly was that used in the determination of the heat of formation of sulfur dioxide [7] and a number of subsequent investigations. The detailed description of the characteristics of this type of calorimeter is given by Dickinson 
[8]. The jacket, containing approximately 11 liters of water, was maintained near $28^{\circ} \mathrm{C}$ at a constant temperature within several thousandths of a degree by means of the automatic regulator previously described [9]. For operation when the temperature of the room was above about $26.5^{\circ} \mathrm{C}$, ice water was made to siphon at a controlled rate through a coil of copper tubing immersed in the water in the jacket, to provide a slight excess of refrigeration, wbich was then balanced automatically by the heating device.

The calorimeter can, supported on three pointed ivory pegs, contained $2873.26 \mathrm{~g}$ of water, the stirrer, platinum resistance thermometer, heater, and the bomb, which contained the hydrocarbon in a sealed glass ampoule, $1 \mathrm{ml}$ of water, and oxygen to a pressure of 30 atm (calculated to $25^{\circ} \mathrm{C}$ ). With the exception of minor variations in the mass of hydrocarbon and of the glass ampoule, the calorimeter system was the same in all the experiments. The stirrer was operated at a substantially constant rate near $285 \mathrm{rpm}$ with a belt drive from a synchronous motor.

The calorimeter heater was made of a cylinder of thin copper, 7.8 $\mathrm{cm}$ in diameter and $7.5 \mathrm{~cm}$ in height, coated on the outside with Pizein [9], over which was wound noninductively about $145 \mathrm{ohms}$ of enameled manganin wire, No. 30 AWG. To the ends of the manganin wire were soldered enameled copper wires, No. 24 AWG, serving as current leads. A second layer of Pizein was then applied. Potential leads, of No. 28 AWG enameled copper wire, were soldered to the current leads midway in the air gap between the calorimeter can and the jacket. These four leads, together with the two firing leads from the bomb, were imbedded in a layer of Pizein placed between two plates of mica, the whole being fastened tightly to the metal jacket by means of a metal plate and fastening screw. The cylindrical heater fitted snugly around the body of the bomb.

\section{(b) THERMOMETRIC SYSTEM}

A new platinum resistance thermometer of the regular flat calorimetric type ${ }^{2}$ was used in conjunction with the new type Mueller resistance bridge ${ }^{3}$ the installation of which was reported previously $[10,11]$. The constants of the thermometer (Serial No. 285,380) were determined by the Thermometry Section of this Bureau in terms of NBS international ohms. Using the factor 1.00046 for conversion to absolute ohms, ${ }^{4}$ and expressing the resistance, $R$, as a function of the temperature, $t$, in degrees centigrade, there is obtained for this thermometer, for the range $0^{\circ}$ to $100^{\circ} \mathrm{C}$, the relation

and

$$
R=25.5057+0.101420 t-0.00001420 t^{2} \text { absolute ohms }
$$

$$
\mathrm{d} R / \mathrm{d} t=0.101420-0.00002840 t .
$$

It should be emphasized that knowledge of the actual relation between resistance and temperature for the given thermometer is not needed for the calorimetric experiments proper, when these are performed over substantially the same interval of resistance at the same mean temperature. Equation 9 is used here only to determine to

Catalog No. 8160, Leeds and Northrup Co., Philadelphia, Pa.

3 Serial No. 404, Eppley Manufacturing Co., Newport, R. I.

"The factor 1.00046 was used in place of the present "best" value of $1.00048[12,13]$ because the values of the resistance coils of the bridge had in manufacture been labeled in absolute ohms derived from the NBS international ohm with the factor 1.00046 [14]. 
$0.01^{\circ} \mathrm{C}$ the temperature to which the observed thermodynamic quantity is to be assigned. Equation 10 indicates that the value of $d R / d t$ changes by only 0.003 percent for a change of $1^{\circ} \mathrm{C}$ in the mean temperature. Actually, substantially all of the experiments of the present investigation had mean temperatures within $0.10^{\circ} \mathrm{C}$ of the selected standard mean temperature, so that this correction would be negligible.

(c) COMBUSTION BOMB

The assembled bomb, shown in figure 1, differs somewhat from those previously described $[8,15,16,17,26,27]$. The body, ${ }^{5} A$, is made of
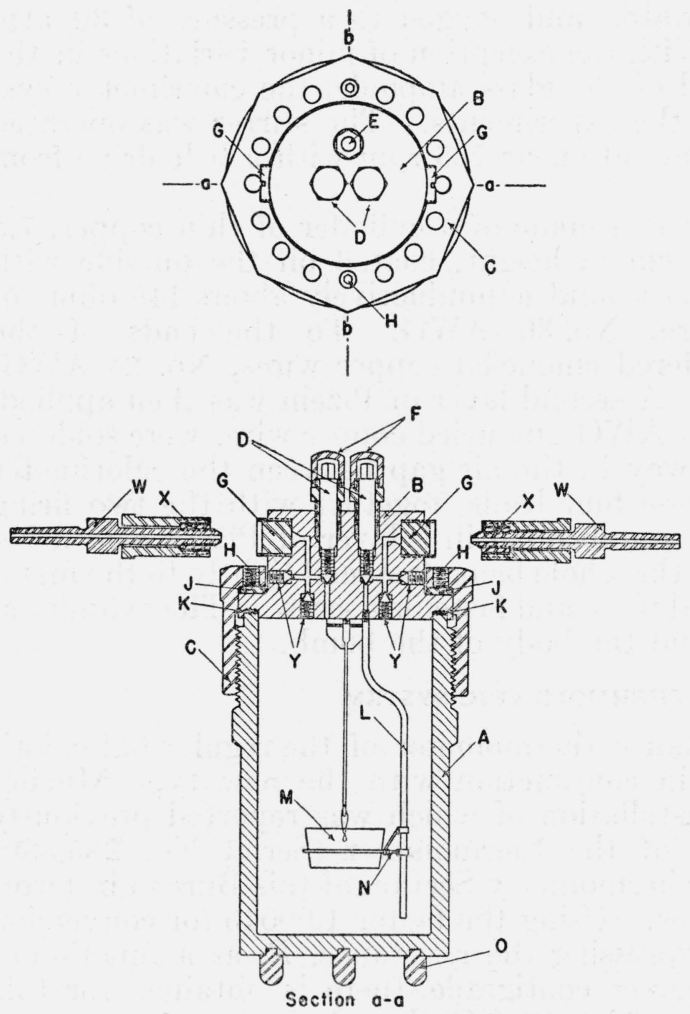
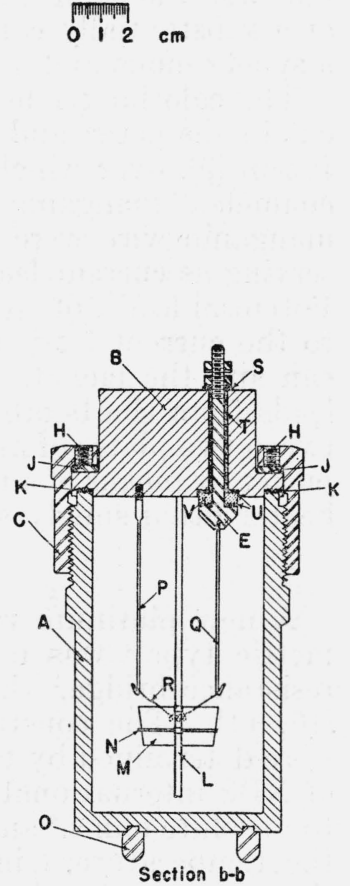

Figure 1. - Drawing of the bomb.

See the text for explanation.

Illium, a corrosion-resistant alloy, and has an internal volume of $385 \mathrm{ml}$. The head, $B$, also of Illium, was designed and made ${ }^{6}$ especially for this bomb. The sleeve, $C$, of stainless steel, serves to hold the head against the body of the bomb. Sixteen headless steel setscrews, $H$, serve to press the hard steel ring, $J$, against the flange of the head, this pressure serving to seal the bomb with the gold gasket, $K$. The two valves, $D$, have stems made of stainless steel, with lead packing. The caps, $F$, of stainless steel, serve to keep water from

${ }^{5}$ Catalog No. 1A, Parr Instrument Co., Moline, Ill.

${ }^{6}$ American Instrument Co., Silver Spring, Md. 
the valves when the bomb is under water. The plugs, $G$, of stainless steel, serve to close the openings to the valves after the bomb is filled with oxygen. The inlet tube, $L$, of platinum, has its end below the platinum cup, $M$, in which is placed the sample to be burned. The cup, $M$, is supported at three points on the ring, $N$, which is made of platinum wire, No. 18 AWG. The electric terminal for ignition, $E$, is made of stainless steel and is insulated from the remainder of the head by means of a Bakelite washer, $S$, a Bakelite sleeve, $T$, and a quartz washer, $V$. The quartz washer, $V$, is bounded by two gold washers, $U$, the upper one being not in direct contact with the insulated terminal. The other electric terminal for ignition is the bomb itself, and the ignition circuit is completed through the platinum wires, $P$ and $Q$ (No. $18 \mathrm{AWG}$ ), and the iron fuse wire, $R$ (No. 36 $\mathrm{AWG}$ ), which latter is held in place by squeezing on it the turned-back ends of the wires $P$ and $Q$. The iron fuse wire $R$ was made with a central coil and straight ends, as shown in the figure. Permanent plugs, $Y$, close the unneeded openings that were made in producing the inlet and outlet passageways. At the times of emptying the bomb, the connections, $X$, are put in place of the plugs, $G$. The ends, $W$, have a standard, 1 in 10 , taper. The bomb is supported by the three stainless steel pegs, $O$, which are $11 \mathrm{~mm}$ in height and provide a reasonable clearance underneath the body of the bomb for circulation of the water.

\section{CHEMICAL PROCEDURE}

\section{PREPARATION OF THE HEXANES}

For each of the five isomeric hexanes, small lots of material were obtained from two independent sources.

The first lots each of $n$-hexane, 2-methylpentane, 3-methylpentane, 2,3-dimethylbutane, and 2,2-dimethylbutane (hereafter labeled " $\mathrm{A}$ " in this paper) were obtained from the Research Laboratories of the General Motors Corporation, through the courtesy of Thomas A. Boyd. The synthesis and purification of these five hexanes have been described by Cramer and Mulligan [18], who reported values for the boiling point, density, and refractive index. Following this, the materials were redistilled from sodium in a small rectifying column by P. L. Cramer, of the General Motors Research Laboratories, and sent to the National Bureau of Standards for this investigation. Before the determination of the heats of combustion of these samples, measurements were made on them of the boiling point, the difference between the temperatures of boiling and condensation, and, for 2methylpentane, 2,2-dimethylbutane, and 2,3-dimethylbutane, the freezing point, by Wojciechowski, who has reported in detail on these properties [19]. On a small part of each of these samples, measurements were also made of the heat capacity in the range from $-185^{\circ}$ to $50^{\circ} \mathrm{C}$ by Stull, who has reported in detail concerning the heat capacities of the solid and liquid states, the heats of fusion for $n$-hexane, 2-methylpentane, and 2,2-dimethylbutane, and the heat of transition for the latter [20]. 
The second lot of $n$-hexane (labeled "B" in this paper) was obtained from B. J. Mair, of this Bureau, who has described its synthesis, purification, and properties [21].

The second lots each of 2-methylpentane, 3-methylpentane, and 2,3-dimethylbutane (labeled "B" in this paper) were obtained from the Experimental Division of the Sun Oil Co., through the courtesy of Johannes H. Bruun. These three hexanes were separated by distillation from a West Virginia natural gasoline by Bruun, Hicks-Bruun, and Faulconer [22], who have described the purification and determined the boiling point, freezing point (for 2-methylpentane and 2,3dimethylbutane), density, and refractive index.

The second lot of 2,2-dimethylbutane (labeled " $\mathrm{B}$ " in this paper) was obtained from the Research Laboratory of the Universal Oil Products Co., through the courtesy of Gustav Egloff and A. V. Grosse. The synthesis and purification of this material have been described by Schmerling, Friedman, and Ipatieff [23] Precise measurements of the refractive index of this material have been obtained by Grosse [24].

In addition to the purification described in the foregoing papers, each of these lots of isomeric hexanes was, before use in the present investigation, filtered through a column of silica gel to remove any possible traces of aromatic hydrocarbons, olefin hydrocarbons, and nonhydrocarbon impurities [25].

No explicit quantitative estimate has been made of the amount of impurity in any of the 10 lots of material measured, except in the case of 2-methylpentane, which was reported by Bruun, Hicks-Bruun, and Faulconer to have a purity greater than 99.99 mole percent [22].

In view of (a) the manner of preparation and purification, (b) the accord of the physical properties of refractive index, density, boiling point, and, where available, the freezing point, with the "best" values recorded in the literature $[18,19,20,21,22,23,28]$, (c) the fact that no significant difference in heat of combustion was observed for the two lots of each of the isomers from independent sources, and (d) the fact that the impurities would be expected to be isomeric hexanes to the presence of which the measurements are not overly sensitive (see following), it may be concluded that the amount of combustible impurity in any of the 10 lots of material was such as to alter the heat of combustion by not more than 5 parts in 100,000. It would be expected from the manner of preparation and purification that the impurities are isomeric hexanes. On this basis, it may be calculated that the amount of one isomer required to be present as impurity in another isomer in order to alter the heat of combustion of the latter by 5 parts in 100,000 (or $0.05 \mathrm{kcal} / \mathrm{mole}$ ) ranges from a minimum of 1.5 mole percent for the pair, $n$-hexane and 2,2-dimethylbutane (which normally boil $19^{\circ} \mathrm{C}$ apart), to a maximum of 8 mole percent for the pair, 2-methylpentane and 3-methylpentane (which normally boil $3^{\circ} \mathrm{C}$ apart).

\section{SEALING OF THE HYDROCARBONS IN GLASS AMPOULES}

For combustion in the liquid state in the bomb, the hydrocarbons were sealed in thin-walled soft-glass ampoules, which are shown in figure 2 in various stages of preparation. These ampoules differ from those described by Richards and Barry [29], and later by Jessup [30], 
in that they are made with two openings, instead of one, in order to facilitate filling. The procedure of making these bulbs is briefly as follows: A round bulb was blown at the end of a tube which had been previously drawn to a thin-walled capillary, as in part 1 of figure 2. The sides of the bulb were then flattened, as in part 2 of figure 2 . A second and smaller opening was then made on the bulb by heating a small area and pulling away the glass, producing the form shown in part 3 of figure 2. The capillary tubes were then cut off to the desired lengths and the tube, $A$, was bent, to form the completed bulb as shown in part 4 of figure 2 .

After drying in an air oven and blowing out with dry air, the empty bulbs were cooled in a desiccator and afterwards weighed - the average weight of one bulb being about $0.2 \mathrm{~g}$. In filling a bulb with the liquid to be burned, the tip $A$ (part 4 of fig. 2) was immersed in the given

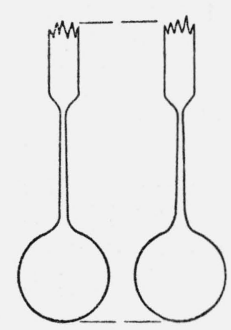

I

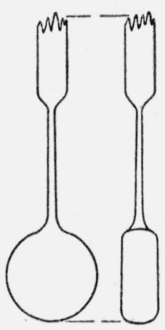

2

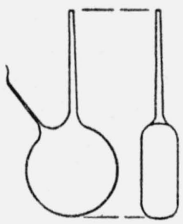

3

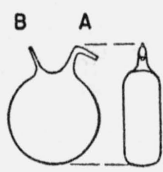

4
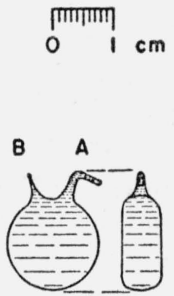

5

FIGURE 2.-Drawing illustrating the steps in making and sealing the glass ampoules.

See the text for explanation.

liquid and a slight suction from a vacuum line was applied at the opening $B$ to draw the liquid into the bulb. After filling, the level of the liquid at $A$ was drawn inward to a distance of about $4 \mathrm{~mm}$ from the tip, by touching a piece of filter paper at the tip $B$. A hot pointed flame was then quickly applied to $A$ and the tip sealed, as shown in part 5 of figure 2. As the tip $A$ cooled, the level of the liquid at $B$ drew away from the tip, usually to a distance of about $3 \mathrm{~mm}$. If the contraction was less than this amount, a piece of ice applied momentarily at the bottom of the bulb served to produce the desired amount of contraction, and the opening at $B$ was then sealed, as shown in part 5 of figure 2. The entire process of filling and sealing one bulb may be easily completed in less than one minute. For the hexanes, the mass of hydrocarbon contained in a bulb was about $0.8 \mathrm{~g}$, or $1.2 \mathrm{ml}$, on the average.

\section{IGNITION OF THE HYDROCARBON}

For combustion in the bomb, the filled and sealed glass bulb containing the hydrocarbon was laid on one of its two flat sides in the cup, shown at $M$ in figure 1 . The iron wire fuse, which in the present experiments consisted of a 5-cm length of No. 36 AWG Parr ignition wire, ${ }^{7}$ was placed with its central coil (see fig. 1) separated by a space of about $1 \mathrm{~mm}$ from the upper flat side of the bulb. An alternating

7 Catalog No. 45C10, Parr Instrument Co., Moline, Ill. 
current at 24 volts, provided by a small transformer on the 110-volt house line, supplied the energy for ignition. At the end of a combustion, the glass of the bulb was found lying at the bottom of the crucible, $M$, in the form of one or more globules, which were clear in some cases and in others darkened by some material distributed through the glass. Following the argument presented by Jessup [30], it was concluded that the quantity of the material, iron oxide or carbon, that produced such darkening was negligible in amount and that the heat effect associated with it was not at all significant. The evaluation of the energy associated with the process of ignition is discussed in Section V-1.

\section{PURIFICATION OF THE OXYGEN USED FOR COMBUSTION}

The oxygen used for the combustion of the hydrocarbons was ordinary commercial oxygen, which was freed of combustible impurities, following the findings of Keffler [31,32] and Jessup and Green [15]. The apparatus used in the present investigation for purifying the oxygen and filling the bomb is shown in the upper part of figure 3. $A$ is the cylinder containing the oxygen under pressure; $B$ is the valve for reducing the pressure to somewhat above $30 \mathrm{~atm}$ and for regulating the rate of flow of the oxygen; $C$ is a high-pressure steel tube,${ }^{8}$ which is electrically heated and contains copper oxide kept at about $500^{\circ} \mathrm{C}$, to oxidize any combustible impurities in the oxygen; $D$ is a coil, which may be immersed in water to cool the oxygen issuing from the oxidizing tube, $C ; E$ is a high-pressure steel tube, ${ }^{9}$ which contains Ascarite (a commercial mixture of sodium hydroxide and asbestos) at room temperature to remove all of the carbon dioxide from the oxygen before it passes into the bomb at $G ; F$ is a Bourdon-type gage for measuring the pressure of the oxygen when the flow of oxygen is stopped and before the bomb is closed. The connecting fittings are of chrome-vanadium steel and the connecting tubing is of chromemolybdenum steel.

Before each filling, the bomb was flushed with the purified oxygen for 15 minutes at a rate of flow of $400 \mathrm{ml}$ (at room temperature and 1 atm) per minute. Then the exit valve of the bomb was closed and the bomb filled with the purified oxygen at a rate that required 15 minutes to attain the final pressure of $30 \mathrm{~atm}$ (calculated to $25^{\circ} \mathrm{C}$ ).

\section{EXAMINATION OF THE PRODUCTS OF COMBUSTION}

The products of each combustion were examined to determine the amount of carbon dioxide formed in the main reaction of combustion in the bomb, the amount of nitric acid formed by oxidation of some of the nitrogen in the oxygen used for combustion, and the amount of carbon dioxide formed by subsequent oxidation of any products of incomplete combustion.

The analytical train used for determining the carbon dioxide is shown in the lower part of figure $3 . H$ is a cylinder (different from $A$ ) containing oxygen under pressure; $I$ is a valve for reducing the pressure to somewhat above $1 \mathrm{~atm}$ and for regulating the flow of oxygen; $J$ is an electrically heated furnace which maintains at about

8 Catalog No. 406-31, American Instrument Co.

- Catalog No. 406-32, American Instrument Co. 
$550^{\circ} \mathrm{C}$ a glass (Corning 172) tube containing copper oxide, to oxidize any combustible impurities in the oxygen; $K$ is a tube containing Ascarite, to remove carbon dioxide; $G$ is the combustion bomb; $L$ is an absorption tube containing anhydrous magnesium perchlorate, backed with a plug of phosphorus pentoxide, to remove water [1]; $M$ is a weighed absorption tube containing Ascarite, backed, in order, with plugs of anhydrous magnesium perchlorate and phosphorus
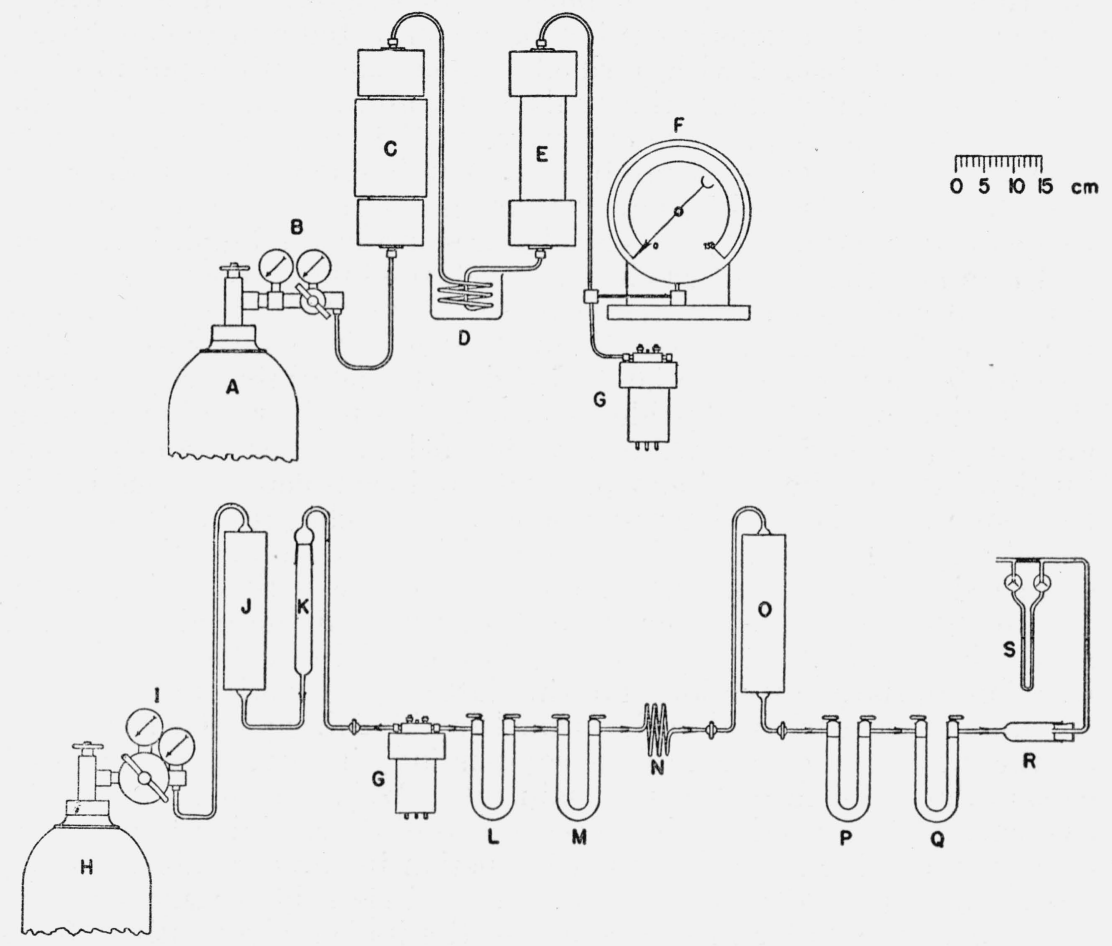

FigURE 3.-Diagram showing the apparatus for filling the bomb with purified oxygen and for analyzing the products of combustion.

See the text for explanation.

pentoxide, to collect the carbon dioxide [1]; $N$ is a flexible glass coil to permit coupling of the tube $M$ to the fixed tube leading to the electrically heated furnace $O$, kept at $550^{\circ} \mathrm{C}$, which is a duplicate of $J$ and serves to oxidize any combustible material remaining in the products of the combustion in the bomb; $P$ is an absorption tube similar to $L ; Q$ is a weighed absorption tube similar to $M ; R$ is a guard tube containing, in order, phosphorus pentoxide, magnesium perchlorate, and Ascarite, to prevent backdiffusion of water vapor or carbon dioxide into the tube $Q$ from the air; $S$ is a calibrated flow meter, discharging to the air of the room, which is used to measure the rate of flow of the oxygen through the system. The analytical train just described is all glass from the valve, $I$, to the guard tube, $R$, with the exception of the metal bomb, $G$, and its metal tapered connections (shown in detail at $W$, $X$ in fig. 1). 
During the period in which, immediately preceding examination of the products of combustion, the analytical train is being flushed with purified oxygen, a straight open tube with appropriate tapered ends serves as a "stand-in" for the bomb at $G$. The analytical train is first flushed with oxygen with the connection between $N$ and $O$ open for about 5 minutes, in order to displace into the air of the room, instead of into the hot furnace $O$, the hydrogen with which the tube $M$ had been filled for purposes of weighing. After a calorimetric combustion experiment has been completed and the analytical train has been flushed with purified oxygen, the bomb is put in place of the "stand-in" tube in the analytical train, as shown at $G$ in the lower part of figure 3 . The exit valve of the bomb is then carefully opened, and the gaseous products of combustion are permitted to issue from it at a rate of about $200 \mathrm{ml}$ (measured at $1 \mathrm{~atm}$ and room temperature) per minute. After the pressure in the bomb is reduced to $1 \mathrm{~atm}$ and the flow of gas has stopped, the inlet valve of the bomb is opened and purified oxygen is passed through the bomb at about the same foregoing rate for about 1 hour. The absorption tubes $M$ and $Q$ are then appropriately weighed to determine, respectively, the amount of carbon dioxide formed in the main reaction and the amount of carbon dioxide, if any, formed in the subsequent combustion in the tube $O$ of any products of incomplete combustion in the bomb. "Blank" determinations of the changes in weight of the absorption tubes $M$ and $Q$, made with the same quantity of oxygen passing through the system as in an actual experiment, indicated, within $\pm 0.00010 \mathrm{~g}$, zero change in the weight of the main tube, $M$, and a change of 0.00010 to $0.00030 \mathrm{~g}$ in the weight of the second tube, Q. Appropriate corrections for this latter were made to determine the amount of carbon dioxide formed in the subsequent combustion of the products of incomplete combustion, if any. The mass of carbon dioxide collected in the main tube, $M$, was near $2.5 \mathrm{~g}$, on the average. In connection with this method of determining the amount of carbon dioxide formed in the combustion in the bomb, Jessup [30] has shown that no significant amount of nitric acid is removed from solution in the water in the bomb by the indicated quantity of gas issuing from the bomb. This is in accord with calculations made by the authors.

The procedure of handling the absorption tubes $M$ and $Q$ was that previously described $[1, a]$, with the tubes filled with dry hydrogen at the times of weighing.

The small amount of nitric acid, formed through oxidation of some of the nitrogen in the oxygen used for combustion and its subsequent reaction with an absorption in water, was determined after the removal of the gaseous products of combustion from the bomb by carefully washing the inside of the bomb with water and titrating the aqueous solution with standard $0.1 N$ aqueous sodium hydroxide.

Occasionally, there occurred an abnormal combustion in which there was formed a relatively large amount of products of incomplete combustion, as measured by the amount of carbon dioxide collected in the second weighed absorption tube ( $Q$ in fig. 3$)$. Such an abnormal experiment was also usually made evident by a higher than normal rate of combustion. It was concluded that in such experiments the glass ampoule containing the hydrocarbon must have been broken prematurely, so that at the time of ignition the bomb was filled with a 
combustible mixture in the gas phase, which produced the accelerated combustion. In several other experiments, which otherwise appeared normal, small but significant amounts of unburned carbon, estimated to be from 0.1 to 0.4 percent of the total, were found in the bomb after combustion. All such abnormal experiments were discarded because either or both the nature and the amount of reaction which actually occurred in the bomb could not be specified.

\section{DETERMINATION OF THE AMOUNT OF REACTION}

For each calorimetric combustion experiment, the amount of reaction was determined-from the mass of carbon dioxide formed, taking 1 mole $(44.010 \mathrm{~g})$ of carbon dioxide as equivalent to one-sixth mole of hexane. With this procedure, it becomes unnecessary to determine and correct for the amount of air and water that may be dissolved in the hydrocarbons. Unless precautions are taken to exclude them, air and water may each dissolve in typical hydrocarbons to the extent of several parts in 10,000 by weight. ${ }^{10}$ In humid weather, it is practically impossible to prepare sealed bulbs containing water-free hydrocarbons.

For those experiments in which the bulbs were filled in dry weather and in which the combustion was normal, the ratio of the mass of hydrocarbon to the mass of carbon dioxide produced had a value equal to that required stoichiometrically, within one or two parts in 10,000, when due allowance was made for air dissolved in the hydrocarbon.

\section{CALORIMETRIC PROCEDURE}

\section{DETERMINATION OF THE IGNITION ENERGY}

The energy added to the calorimeter by the melting and burning of the iron fuse wire was determined in a series of blank experiments in which the calorimeter was at a temperature slightly below that of the jacket, and in which the bomb was charged with purified oxygen to a pressure of $30 \mathrm{~atm}$ as in a regular combustion experiment. There were determined the corrected increase in resistance of the platinum resistance thermometer produced by the addition of the ignition energy to the standard calorimeter system, and the mass of any iron wire unburned. Correction to a standard amount of iron wire burned was made using the value 6.63 kilojoules/g for the heat of combustion of the iron wire in oxygen in the bomb.

In table 1 are given the results of 10 experiments to determine the increase in temperature of the standard calorimeter system, expressed as the increase in resistance in ohms of the given platinum resistance thermometer, produced by the standard ignition process. In table 1, the various columns give, respectively, the number of the experiment; the mass of iron wire burned; $\Delta r_{i}$, the corrected increase in temperature of the standard calorimeter system, expressed as the increase in resistance in ohms of the platinum resistance thermometer; the correction to the standard amount of iron wire burned, $0.00760 \mathrm{~g}$; the value of $\Delta r_{i}$ for the standard ignition process, in ohms; and the deviation from the mean. The energy of this standard ignition process is about

\footnotetext{
10 See, for example, Moore, Renquist, and Parks [33].
} 
$1 / 700$ th of the heat evolved in a calorimetric combustion experiment. In determining the absolute value of the heat of combustion of a given hydrocarbon, the entire energy of the ignition process is significant; but in determining the ratios of the heats of combustion of various isomers, as in the present investigation, the energy of ignition substantially cancels because it is in all experiments nearly a constant fraction of the total heat evolved.

TABLE 1.-Results of the experiments to determine the change in temperature of the standard calorimeter system produced by the standard ignition process

\begin{tabular}{|c|c|c|c|c|c|}
\hline Experiment & $\begin{array}{l}\text { Mass of iron } \\
\text { wire burned }\end{array}$ & $\Delta r_{i}$ & $\begin{array}{l}\text { Correction to } \\
0.00760 \mathrm{~g} \text {, wire } \\
\text { burned }\end{array}$ & $\begin{array}{l}\Delta r_{i} \text { for the } \\
\text { standard igni- } \\
\text { tion process }\end{array}$ & $\begin{array}{l}\text { Deviation } \\
\text { from mean }\end{array}$ \\
\hline $\begin{array}{l}1 \\
2 \\
4 \\
5\end{array}$ & $\begin{array}{r}g \\
0.00774 \\
.00763 \\
.00773 \\
.00774 \\
.00782\end{array}$ & $\begin{array}{r}\text { Ohm } \\
0.000413 \\
.000417 \\
.000408 \\
.000422 \\
.000427\end{array}$ & $\begin{array}{l}\text { Ohm } \\
-0.000007 \\
-.000001 \\
-.000006 \\
-.000007 \\
-.000011\end{array}$ & $\begin{array}{l}\text { Ohm } \\
0.000406 \\
.000416 \\
.000402 \\
.000415 \\
.000416\end{array}$ & $\begin{array}{r}\text { Ohm } \\
-0.000005 \\
.000005 \\
-.000009 \\
.000004 \\
.000005\end{array}$ \\
\hline $\begin{array}{l}6 \\
6 \\
8 \\
8 \\
9 \\
10\end{array}$ & $\begin{array}{l}.00771 \\
.00774 \\
.00779 \\
.00759 \\
.00775\end{array}$ & $\begin{array}{l}.000411 \\
.000417 \\
.000423 \\
.000407 \\
.000420\end{array}$ & $\begin{array}{r}-.000005 \\
-.000007 \\
-.000009 \\
.000000 \\
-.000007\end{array}$ & $\begin{array}{l}.000406 \\
.000410 \\
.000414 \\
.000407 \\
.000413\end{array}$ & $\begin{array}{r}-.000005 \\
-.000001 \\
.000003 \\
-.000004 \\
.000002\end{array}$ \\
\hline \multicolumn{4}{|c|}{$\begin{array}{l}\text { Mean } \\
\text { Standard deviation of the mean }\end{array}$} & $\begin{array}{r}0.000411 \\
\pm 0.000001_{6}\end{array}$ & \\
\hline
\end{tabular}

\section{COMBUSTION EXPERIMENTS}

The following procedure was followed in performing a calorimetric combustion experiment: The two absorption tubes for carbon dioxide ( $M$ and $Q$ in fig. 3) were prepared, flushed with hydrogen, and weighed [1a, 34]. The sealed glass bulb (part 5 in fig. 2) containing the hydrocarbon, and the iron fuse wire, were weighed and then placed in position below the bead of the bomb (see fig. 1). One milliliter of water was placed in the bottom of the body of the bomb. The head of the bomb, $B$, carrying the gold gasket, $K$, in its groove, was placed in position on the body. The hard steel ring, $J$, was placed on the head, and the stainless steel collar, $C$, was screwed by hand down on the body over the head. The collar, $C$, was then screwed back an amount equal to about $2 \mathrm{~mm}$ on the periphery. The actual sealing of the bomb to pressure was accomplished by screwing down the 16 set screws, $H$, through the collar against the steel ring, $J$. These screws were tightened gradually, by means of a hexagon socket setscrew wrench, in the usual manner of proceeding from a given setscrew to the one most distant from it, then to that one of the remaining setscrews most distant from the preceding one, and so on. The bomb was placed in the position shown at $G$ in the upper part of figure 3, purified oxygen was passed through it for 15 minutes, the exit valve was closed, and the bomb was filled, to a pressure of 30 -atm at $25^{\circ} \mathrm{C}$, in a period of 15 minutes. After equilibrium was established and the pressure in the bomb adjusted to the standard value, the inlet valve of the bomb was closed. The standard mass of water, $2873.26 \pm 0.02 \mathrm{~g}$, was weighed in the calorimeter can on the pan of a 5-kg balance having a sensitivity 
for this load of $0.008 \mathrm{~g}$ per scale division. The calorimeter can was placed in the calorimeter and the bomb was lowered into it, with the electric heating coil in position around the body of the bomb, and the calorimeter can was covered.

With the temperature of the jacket of the calorimeter maintained constant at $28.02^{\circ} \mathrm{C}$ within about $\pm 0.002^{\circ} \mathrm{C}$, the combustion experiments were performed with an initial temperature near $25.00^{\circ} \mathrm{C}$ and a final temperature slightly below the temperature of the jacket. The calorimetric observations were as usual divided into three parts: (a) a "fore" period of 20 minutes, in which observations were made every 2 minutes; (b) a "reaction" period of 16 minutes, in which the combustion occurred, followed by a reestablishment of thermal equilibrium in the calorimeter; and (c) an "after" period of 20 minutes, in which observations were made every 2 minutes. In the first 5 minutes of the "reaction" period, observations were made of the time, to the nearest second, at which the resistance of the thermometer attained certain preselected values. At these given times, marked by audible seconds signals, observations were made of the deflection on the galvanometer scale. In this way, there was easily obtained, during the period when the temperature of the calorimeter was changing at the rapid rate of $0.004 \mathrm{ohm}\left(0.04^{\circ} \mathrm{C}\right)$ per second, the resistance on the given audible second without the necessity of watching the galvanometer scale and the clock simultaneously. During this 5-minute interval, observations were made for the following values of resistance, in ohms, on the bridge: 28.04 (on the 20th minute), 28.05, 28.10, 28.15, 28.20, 28.25, 28.28, $28.30,28.31,28.32$, and 28.32 (on the 25 th minute). These intervals in ${ }^{\circ} \mathrm{C}$ are, respectively, $0.1,0.5,0.5,0.5,0.5,0.3,0.2,0.1,0.1$, and 0.0 . During the last 11 minutes of the "reaction" period, when the temperature change was very small, observations were made every minute. At the end of the "after" period, the temperature of the jacket was measured with the calorimeter thermometer. Upon completion of the calorimetric observations, the bomb was placed in the analytical train, as shown at $G$ in the lower part of figure 3, and determination was made of the amount of reaction and of the amount of incomplete combustion, if any.

The value of $\Delta \dot{R}_{c}$ (see section III-1) was determined as described on page 610 of reference [35] and page 17 of reference [34], with the value being retained in ohms at a given mean temperature instead of being converted to degrees. The average temperature, with respect to time, of the calorimeter during the "reaction" period was determined from a time-temperature plot, using 20 -second intervals for the first 5 minutes and longer intervals for the remaining time. If the mean of the initial and final temperatures of the experiment differs significantly from the standard mean temperature, the observed value of $\Delta R_{c}$ needs (a) to be increased by 3 parts per million for each $0.1^{\circ} \mathrm{C}$ $(\sim 0.01 \mathrm{ohm})$ positive difference between such mean temperatures, due to the change in the value of $d R / d t$ (see eq 10), and (b) to be increased by 5 parts per million for the same departure from the standard mean temperature due to the change in the energy equivalent of the calorimeter system with temperature. 


\section{CORRECTION FOR THE FORMATION OF NITRIC ACID}

The value of $\Delta r_{n}$ (see section III-1), which is the rise in temperature of the calorimeter system produced by the heat evolved in the formation of a small amount of nitric acid, according to the reaction

$$
1 / 2 \mathrm{~N}_{2}(\mathrm{~g})+1 / 2 \mathrm{H}_{2} \mathrm{O} \text { (liq) }+5 / 4 \mathrm{O}_{2}(\mathrm{~g})=\mathrm{HNO}_{3}(\mathrm{aq}),
$$

was calculated from the amount of nitric acid formed, determined as described in section IV-5, using the value $57.8 \mathrm{kj} / \mathrm{mole}$ for the heat evolved in the formation of dilute aqueous nitric acid in the bomb process. In determining the absolute value of the heat of combustion of a given hydrocarbon, the entire energy associated with the formation of nitric acid is significant; but in determining the ratios of the heats of combustion of various isomers, the value of $\Delta r_{n}$ substantially cancels because it is in all experiments nearly a constant fraction $(0.0001)$ of the value of $\Delta R_{c}$.

\section{RESULTS OF THE PRESENT INVESTIGATION}

The experimental results of the present investigation, giving values of $B=q / E_{s}$ as defined by eq 4 , are presented in tables $2,3,4,5$, and 6 for $n$-hexane, 2-methylpentane, 3-methylpentane, 2,3-dimethylbutane, and 2,2-dimethylbutane, respectively. The symbols at the heads of the columns in these tables are defined in section III-1 of this paper, on page 610 of reference [35], or on page 17 of reference [34]. In 6 of the 48 experiments, as indicated in the footnotes marked " $\mathrm{b}$ ", in tables 3,4 , and 6 , a correction (plus) was made to the observed value of $\Delta R$ to take account of a small amount of incomplete combustion, determined as described in section IV-5 of this paper. This correction is concerned only with the deficiency in heat energy resulting from the small amount of incomplete combustion, and its value was calculated on the assumption that the product of incomplete combustion was carbon monoxide. If some of the hydrogen in the original hydrocarbon was not completely oxidized to water, the correction as made would be too small. In these six experiments, the number of moles of hydrocarbon participating in the combustion was measured stoichiometrically by adding the small amount of carbon dioxide (collected in tube $Q$, fig. 3) to the principal amount of carbon dioxide (collected in tube $M$, fig. 3 ). 
TABLE 2.-n-Hexane

\begin{tabular}{|c|c|c|c|c|c|c|c|c|c|}
\hline $\begin{array}{l}\text { Ex- } \\
\text { peri- } \\
\text { ment }\end{array}$ & $\begin{array}{l}\text { Mass of } \\
\text { carbon } \\
\text { dioxide } \\
\text { formed }\end{array}$ & $k$ & $K$ & $U$ & $\Delta R_{0}$ & $\Delta r_{i}$ & $\Delta r_{n}$ & $B$ a & $\begin{array}{l}\text { Deviation } \\
\text { from mean }\end{array}$ \\
\hline $\begin{array}{l}1 \mathrm{~A} \\
2 \mathrm{~A} \\
3 \mathrm{~A} \\
4 \mathrm{~A}\end{array}$ & $\begin{aligned} \stackrel{g}{g} \\
2.26163 \\
2.23988 \\
2.33612 \\
2.61928\end{aligned}$ & $\begin{array}{c}\min ^{-1} \\
0.001927 \\
.001930 \\
.001930 \\
.001935\end{array}$ & $\begin{array}{c}\text { Ohm } \\
0.001915 \\
.001974 \\
.001639 \\
.000785\end{array}$ & $\begin{array}{c}\text { Ohm } \\
0.000138 \\
.000094 \\
.000107 \\
.000080\end{array}$ & $\begin{array}{c}\text { Ohm } \\
0.258934 \\
.256553 \\
.267541 \\
.299854\end{array}$ & $\begin{array}{c}\text { Ohm } \\
0.000416 \\
.000398 \\
.000428 \\
.000413\end{array}$ & $\begin{array}{c}\text { Ohm } \\
0.000028 \\
.000027 \\
.000027 \\
.000028\end{array}$ & $\begin{array}{c}\mathrm{Ohm} / \mathrm{o} \mathrm{CO} \\
0.1143064 \\
.1143604 \\
.1143420 \\
.1143292\end{array}$ & $\begin{array}{r}\mathrm{Ohm} / \mathrm{g} \mathrm{CO} \\
-0.0000248 \\
.0000292 \\
.0000108 \\
-0000020\end{array}$ \\
\hline $\begin{array}{l}5 \mathrm{~B} \\
6 \mathrm{~B}-\ldots \\
7 \mathrm{~B}-\ldots \\
8 \mathrm{~B}-\ldots \\
9 \mathrm{~B} \\
10 \mathrm{~B}\end{array}$ & $\begin{array}{l}2.46001 \\
2.50299 \\
2.63480 \\
2.64505 \\
2.69685 \\
2.72779\end{array}$ & $\begin{array}{r}.001929 \\
.001940 \\
.001931 \\
.001932 \\
.001929 \\
.001943\end{array}$ & $\begin{array}{l}.001255 \\
.001122 \\
.001019 \\
.001007 \\
.000854 \\
.000711\end{array}$ & $\begin{array}{r}.000115 \\
.000130 \\
.000098 \\
.000152 \\
.000131 \\
.000114\end{array}$ & $\begin{array}{l}.281662 \\
.286537 \\
.301673 \\
.302876 \\
.308690 \\
.312217\end{array}$ & $\begin{array}{l}.000415 \\
.000418 \\
.000421 \\
.000417 \\
.000417 \\
.000416\end{array}$ & $\begin{array}{r}.000027 \\
.000027 \\
.000027 \\
.000028 \\
.000028 \\
.000028\end{array}$ & $\begin{array}{r}.1143314 \\
.1143155 \\
.1143426 \\
.1143553 \\
.1143160 \\
.1143136\end{array}$ & $\begin{array}{r}.0000002 \\
-.0000157 \\
.0000114 \\
.0000241 \\
-.0000152 \\
-.0000176\end{array}$ \\
\hline Cea & & & & & & & & $\begin{array}{r}0.1143312 \\
\pm 0.0000059\end{array}$ & \\
\hline
\end{tabular}

- Corrected to the standard calorimetric system and to $28.00^{\circ} \mathrm{C}$.

TABLE 3.-2-Methylpentane

\begin{tabular}{|c|c|c|c|c|c|c|c|c|c|}
\hline $\begin{array}{l}\text { Ex- } \\
\text { peri- } \\
\text { ment }\end{array}$ & $\begin{array}{l}\text { Mass of } \\
\text { carbon } \\
\text { dioxide } \\
\text { formed }\end{array}$ & $k$ & $K$ & $U$ & $\Delta R_{\text {. }}$ & $\Delta_{i-}$ & $\Delta r_{n}$ & $B \mathrm{~s}$ & $\begin{array}{l}\text { Deviation } \\
\text { from mean }\end{array}$ \\
\hline 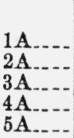 & $\begin{array}{l}\stackrel{g}{2} \\
2.44276 \\
2.62544 \\
2.47285 \\
2.65991 \\
2.38014\end{array}$ & $\begin{array}{c}\min ^{-1} \\
0.001942 \\
.001943 \\
.001948 \\
.001940 \\
.001930\end{array}$ & $\begin{array}{c}\text { Ohm } \\
0.001334 \\
.001009 \\
.001178 \\
.000609 \\
.001642\end{array}$ & $\begin{array}{c}\text { Ohm } \\
0.000171 \\
.000206 \\
.000213 \\
.000221 \\
.000042\end{array}$ & $\begin{array}{c}\text { Ohm } \\
0.279250 \\
.300232 \\
.282802 \\
.304179 \\
.272217\end{array}$ & $\begin{array}{c}\text { Ohm } \\
0.000419 \\
.000399 \\
.000409 \\
.000411 \\
.000414\end{array}$ & $\begin{array}{c}\text { Ohm } \\
0.000028 \\
.000028 \\
.000027 \\
.000034 \\
.000079\end{array}$ & $\begin{array}{c}\mathrm{Ohm} / \mathrm{gCO} \mathrm{CO} \\
0.1141491 \\
.1142093 \\
.1142021 \\
.1142134 \\
.1141763\end{array}$ & $\begin{array}{r}\text { Ohm/g CO } \\
-0.0000325 \\
.0000277 \\
.0000205 \\
.0000318 \\
-.0000053\end{array}$ \\
\hline $\begin{array}{l}6 \mathrm{~B} \\
\text { 7B-..- } \\
8 \mathrm{~B}-. .\end{array}$ & $\begin{array}{l}2.50963 \\
2.44313 \\
2.61464\end{array}$ & $\begin{array}{l}.001931 \\
.001939 \\
.001941\end{array}$ & $\begin{array}{l}.001064 \\
.001298 \\
.001023\end{array}$ & $\begin{array}{l}.000227 \\
.000242 \\
.000242\end{array}$ & $\begin{array}{l}.286905 \\
.279363 \\
.298831\end{array}$ & $\begin{array}{l}.000420 \\
.000410 \\
.000423\end{array}$ & $\begin{array}{l}.000027 \\
.000026 \\
.000030\end{array}$ & $\begin{array}{r}.1141597 \\
.1141834 \\
+.1141591\end{array}$ & $\begin{array}{r}-.0000219 \\
.0000018 \\
-.0000225\end{array}$ \\
\hline ear & & & & & & & & $\begin{array}{r}0.1141816 \\
\pm 0.0000087\end{array}$ & \\
\hline
\end{tabular}

- Corrected to the standard calorimetric system _nd to $28.00^{\circ} \mathrm{C}$.

b Corrected (see text, section VI) for a small amount of incomplete combustion: 0.004 percent in 4A and 0.019 percent in $8 \mathrm{~B}$.

TABLE 4.-3-Methylpentane

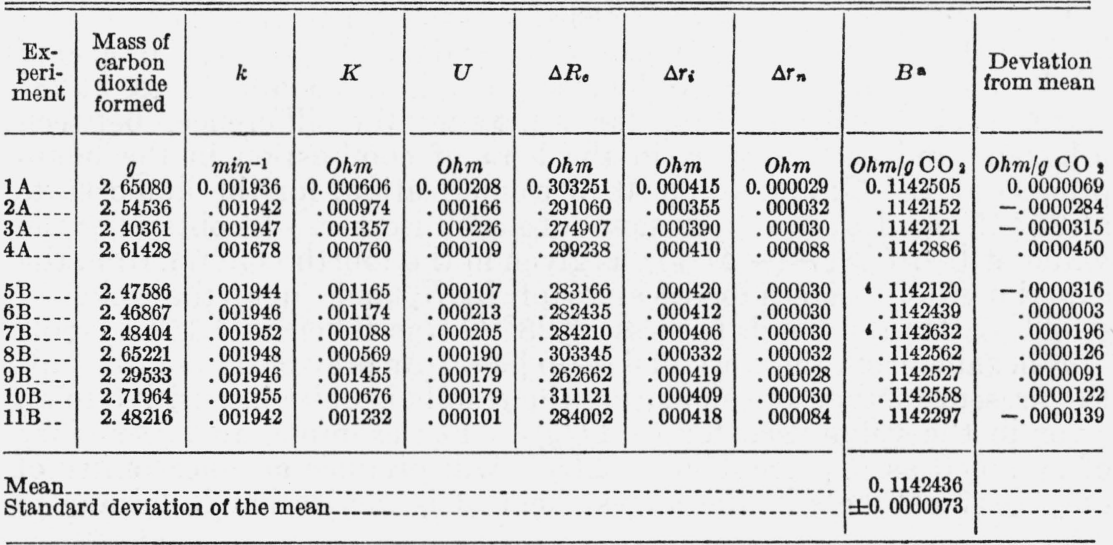

- Corrected to the standard calorimetric system and to $28.00^{\circ} \mathrm{C}$

b Corrected (see text, section VI) for a small amount of incomplete combustion: 0.006 percent in 5B and 0.007 percent in $7 \mathrm{~B}$. 
TABLE 5.-2,8-Dimethylbutane

\begin{tabular}{|c|c|c|c|c|c|c|c|c|c|}
\hline $\begin{array}{l}\text { Ex- } \\
\text { peri- } \\
\text { ment }\end{array}$ & $\begin{array}{l}\text { Mass of } \\
\text { carbon } \\
\text { dioxide } \\
\text { formed }\end{array}$ & $k$ & $K$ & $U$ & $\Delta R_{e}$ & $\Delta r_{i}$ & $\Delta r_{n}$ & $B$ a & $\begin{array}{l}\text { Deviation } \\
\text { from mean }\end{array}$ \\
\hline $\begin{array}{l}1 \mathrm{~A}-- \\
2 \mathrm{~A} \\
3 \mathrm{~A}\end{array}$ & $\begin{array}{c}g \\
2.38849 \\
2.70214 \\
2.43248 \\
2.61965 \\
2.65276\end{array}$ & $\begin{array}{c}\min ^{-1} \\
0.001937 \\
.001947 \\
.001939 \\
.001939 \\
.001937\end{array}$ & $\begin{array}{c}\text { Ohm } \\
0.001421 \\
.000689 \\
.001243 \\
.000665 \\
.000798\end{array}$ & $\begin{array}{c}\text { Ohm } \\
0.000130 \\
.000106 \\
.000107 \\
.000123 \\
.000024\end{array}$ & $\begin{array}{c}\text { Ohm } \\
0.272939 \\
.308700 \\
.278041 \\
.299279 \\
.303209\end{array}$ & $\begin{array}{c}\text { Ohm } \\
0.000418 \\
.000414 \\
.000411 \\
.000403 \\
.000414\end{array}$ & $\begin{array}{c}\text { Ohm } \\
0.000030 \\
.000030 \\
.000029 \\
.000030 \\
.000089\end{array}$ & $\begin{array}{c}\mathrm{O} h \mathrm{~m} / \mathrm{g} \mathrm{CO}_{2} \\
0.1141003 \\
.1140979 \\
.1141389 \\
.1140979 \\
.1141297\end{array}$ & $\begin{array}{r}\mathrm{Ohm} / \mathrm{g} \mathrm{CO} \\
-0.0000038 \\
-.0000062 \\
.0000348 \\
-.0000062 \\
.0000256\end{array}$ \\
\hline 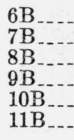 & $\begin{array}{l}2.49910 \\
2.42879 \\
2.28523 \\
2.35109 \\
2.50122 \\
2.45434\end{array}$ & $\begin{array}{l}.001943 \\
.001940 \\
.001939 \\
.001930 \\
.001940 \\
.001938\end{array}$ & $\begin{array}{l}.000996 \\
.001241 \\
.001383 \\
.001508 \\
.001039 \\
.001414\end{array}$ & $\begin{array}{l}.000104 \\
.000152 \\
.000139 \\
.000155 \\
.000120 \\
.000083\end{array}$ & $\begin{array}{l}.285491 \\
.277448 \\
.261198 \\
.268781 \\
.285752 \\
.280441\end{array}$ & $\begin{array}{l}.000417 \\
.000402 \\
.000410 \\
.000413 \\
.000409 \\
.000414\end{array}$ & $\begin{array}{l}.000029 \\
.000028 \\
.000030 \\
.000028 \\
.000030 \\
.000085\end{array}$ & $\begin{array}{l}1140777 \\
.1140717 \\
.1141206 \\
.1141492 \\
.1140874 \\
.1140737\end{array}$ & $\begin{array}{r}-.0000264 \\
-.0000324 \\
.0000165 \\
.0000451 \\
-.0000167 \\
-.0000304\end{array}$ \\
\hline \multicolumn{9}{|c|}{$\begin{array}{l}\text { Mean } \\
\text { Standard deviation of the mean } \\
0.0000081\end{array}$} & \\
\hline
\end{tabular}

a Corrected to the standard calorimetric system and to $28.00^{\circ} \mathrm{C}$.

TABLE 6.-2,2-Dimethylbutane

\begin{tabular}{|c|c|c|c|c|c|c|c|c|c|}
\hline $\begin{array}{l}\text { Ex- } \\
\text { peri- } \\
\text { ment }\end{array}$ & $\begin{array}{l}\text { Mass of } \\
\text { carbon } \\
\text { dioxide } \\
\text { formed }\end{array}$ & $k$ & $K$ & $U$ & $\Delta R_{c}$ & $\Delta r_{i}$ & $\Delta r_{n}$ & $B$ a & $\begin{array}{l}\text { Deviation } \\
\text { from mean }\end{array}$ \\
\hline $\begin{array}{l}1 \mathrm{~A} \\
2 \mathrm{~A} \\
3 \mathrm{~A}\end{array}$ & $\begin{array}{c}\stackrel{g}{ } \\
2.42873 \\
2.35890 \\
2.34257\end{array}$ & $\begin{array}{r}\min ^{-1} \\
0.001955 \\
.001942 \\
.001947\end{array}$ & $\begin{array}{c}\text { Ohm } \\
0.001282 \\
.001184 \\
.001273\end{array}$ & $\begin{array}{r}\text { Ohm } \\
0.000102 \\
.000114 \\
.000123\end{array}$ & $\begin{aligned} & \text { Ohm } \\
& 0.277138 \\
& .269227 \\
& .267265\end{aligned}$ & $\begin{array}{c}\text { Ohm } \\
0.000413 \\
.000410 \\
.000421\end{array}$ & $\begin{array}{r}\text { Ohm } \\
0.000028 \\
.000028 \\
.000029\end{array}$ & $\begin{array}{c}\mathrm{Ohm} / \mathrm{g} \mathrm{CO}_{2} \\
0.1139426 \\
.1139627 \\
\text { b. } 1139203\end{array}$ & $\begin{array}{r}\mathrm{Ohm} / \mathrm{g} \mathrm{CO} 2 \\
0.0000144 \\
.0000345 \\
-.0000079\end{array}$ \\
\hline $\begin{array}{l}4 \mathrm{~B} \\
5 \mathrm{~B}-\cdot- \\
6 \mathrm{~B}-\cdot \\
7 \mathrm{~B}- \\
8 \mathrm{~B}- \\
\end{array}$ & $\begin{array}{l}2.51852 \\
2.50422 \\
2.55891 \\
2.45337 \\
2.38917\end{array}$ & $\begin{array}{l}.001947 \\
.001947 \\
.001947 \\
.001945 \\
.001942\end{array}$ & $\begin{array}{r}.001008 \\
.001023 \\
-.000082 \\
.001190 \\
.001385\end{array}$ & $\begin{array}{l}.000112 \\
.000122 \\
.000125 \\
.000120 \\
.000114\end{array}$ & $\begin{array}{l}.287345 \\
.285653 \\
.291843 \\
.279934 \\
.272578\end{array}$ & $\begin{array}{l}.000412 \\
.000412 \\
.000414 \\
.000421 \\
.000413\end{array}$ & $\begin{array}{r}.000030 \\
.000030 \\
.000030 \\
.000028 \\
.000032\end{array}$ & $\begin{array}{r}.1139345 \\
\text { ь. } 1139146 \\
.1138983 \\
.1139347 \\
.1139177\end{array}$ & $\begin{array}{r}.0000063 \\
-.0000136 \\
-.0000299 \\
-.0000065 \\
-.0000105\end{array}$ \\
\hline \multicolumn{9}{|c|}{$\begin{array}{l}\text { Mean } \\
\text { Standard deviation of the mean }\end{array}$} & \\
\hline
\end{tabular}

a Corrected to the standard calorimetric system and to $28.00^{\circ} \mathrm{C}$.

b Corrected (see text, section VI) for a small amount of incomplete combustion: 0.0026 percent in $3 \mathrm{~A}$ and 0.005 percent in $5 \mathrm{~B}$.

In table 7 are given for the five isomers of hexane values for the following: the constant $B$ in ohms/g $\mathrm{CO}_{2}$, as defined by eq 4 ; the ratio of the heat evolved, per mole of hydrocarbon, in the bomb process at $28^{\circ}$ $\mathrm{C}$ for each isomer to that for $n$-hexane; the difference, between $n$-hexane and each isomer, in the heat of combustion in the bomb process at $28^{\circ} \mathrm{C}$; and the heat of isomerization, for the liquid state at $25^{\circ} \mathrm{C}$ and $1 \mathrm{~atm}$, of $n$-hexane into each isomer. In obtaining the value of $\left(-\Delta U_{B}\right)_{n}-\left(-\Delta U_{B}\right)_{i}$, as given in the fourth column, from the experimentally determined values of $B_{n} / B_{i}$ and eq 6 , the value of $\left(-\Delta U_{B}\right)_{n}$ for the bomb process at $28^{\circ} \mathrm{C}$ was taken as $4,152 \mathrm{kj} / \mathrm{mole}$ of $n$-hexane, from the work of Jessup [30]. As previously pointed out, the present method of calculating the results is quite insensitive to an error in the value used for $\left(-\Delta U_{B}\right)_{n}$. For example, an uncertainty of as much as $1 / 2$ percent in $\left(-\Delta U_{B}\right)_{n}$ will produce an uncertainty of only $\pm 17 \mathrm{cal} / \mathrm{mole}$ in the largest heat of isomerization ( $n$-hexane to 
2,2-dimethylbutane), which is to be compared with the assigned uncertainty of about 10 times this amount. The values in column 5 differ from those in column 4 because of the difference in the heat capacities of the several isomeric hexanes in the liquid state over the range $25^{\circ}$ to $28^{\circ} \mathrm{C}$. While not actually significant here, these differences were made for the sake of completeness. Both the Washburn conversion to zero pressure [43] and the conversion of $\Delta U$ to $(\Delta U+P V)$ $=\Delta H$ are the same for the several isomers.

TABLE 7.-Heats of isomerization of the five hexanes in the liquid state ${ }^{\text {a }}$

\begin{tabular}{|c|c|c|c|c|c|}
\hline Substance & $B$ at $28.00^{\circ} \mathrm{C}$ & $\begin{array}{l}\text { Ratio of the heats } \\
\text { of combustion } \\
\text { in the bomb } \\
\text { process } B_{i} / B_{n} \\
\text { at } 28.00^{\circ} \mathrm{C}\end{array}$ & $\begin{array}{c}\text { Difference in } \\
\text { the heats of } \\
\text { combustion } \\
\text { in the bomb } \\
\text { process b } \\
\left(-\Delta U_{B}\right)_{n}-\end{array}$ & \multicolumn{2}{|c|}{$\begin{array}{l}\text { Heat of isomerization of the } \\
\text { liquid } H_{i}^{\circ}(\text { liq })-H_{n}^{\circ} \text { (liq) } \\
\text { at } 25.00^{\circ} \mathrm{C}\end{array}$} \\
\hline$n$-Hexane & $\begin{array}{c}\text { Ohm/g CO } \mathrm{CO}_{2} \\
0.1143312 \pm 0.0000118\end{array}$ & 1. 000000 & $\begin{array}{c}\mathrm{kj} / \mathrm{mole} \\
0\end{array}$ & $\begin{array}{r}\text { kj/mole } \\
0\end{array}$ & $\begin{array}{c}k c a l / m o l e \\
0\end{array}$ \\
\hline 2-Methylpentane... & $.1141816 \pm 0.0000174$ & $0.998692 \pm 0.000210$ & $5.43 \pm 0.87$ & $-5.44 \pm 0.87$ & $-1.30 \pm 0.21$ \\
\hline 3-Methylpentane...- & $.1142436 \pm 0.0000146$ & $.999234 \pm 0.000188$ & $3.18 \pm 0.78$ & $-3.16 \pm 0.78$ & $-0.76 \pm 0.19$ \\
\hline 2,3-Dimethylbutane & $.1141041 \pm 0.0000162$ & $.998014 \pm 0.000200$ & $8.25 \pm 0.83$ & $-8.25 \pm 0.83$ & $-1.06 \pm 0.20$ \\
\hline 2,2-Dimethylbutane & $.1139282 \pm 0.0000140$ & $.996475 \pm 0.000183$ & $14.64 \pm 0.76$ & $-14.61 \pm 0.76$ & $-3.49 \pm 0.18$ \\
\hline
\end{tabular}

a All the uncertainties given in this table are equal to twice the standard deviation [6]. The uncertainty to be assigned to the value for the heat of isomerization of any one of the isomers into any other one is substantially the same as that for the isomerization of $n$-hexane into any one of the isomers, namely, about $\pm 0.19 \mathrm{kcal} / \mathrm{mole}$ for the liquid at $25^{\circ} \mathrm{C}$.

b Obtained by subtracting the value in column 3 from unity and multiplying with the factor 4152 (see sections III-1 and VI).

In table 8 are given values for the following: the heat of isomerization, for the liquid state at $25^{\circ} \mathrm{C}$, of $n$-hexane into each isomer, as given in table 7 ; the difference, between $n$-hexane and each isomer, in the heat of vaporization at $25^{\circ} \mathrm{C}$ for the gas in the ideal state; and, finally, the heat of isomerization, for the ideal gaseous state at $25^{\circ} \mathrm{C}$, of $n$-hexane into each isomer. The values given in table 8 for the difference in the heats of vaporization are taken from a study and correlation that are being made [42] of all the available data for all of the paraffin hydrocarbons.

TABLE 8.-Heats of isomerization of the five hexanes in the gaseous state

\begin{tabular}{|c|c|c|c|c|}
\hline Substance & \multicolumn{2}{|c|}{$\begin{array}{c}\text { Heat of isomerization } \\
\text { of the liquid } \\
H_{i} \text { (liq) }-H_{n}^{\circ} \text { (liq) at } 25^{\circ} \mathrm{C}\end{array}$} & \multirow{2}{*}{$\begin{array}{c}\text { Difference in the } \\
\text { heats of vapori- } \\
\text { zation } \\
\left(\Delta H^{\circ} \text { vap }\right)_{n-}- \\
\left(\Delta H^{\circ} \text { vap }\right)_{i} \\
\text { at } 25^{\circ} \mathrm{C} \\
\\
\\
\text { kcal/mole } \\
0 \\
0.38 \pm 0.10 \\
.33 \pm 0.10 \\
.62 \pm 0.10 \\
.95 \pm 0.10\end{array}$} & \multirow{2}{*}{$\begin{array}{c}\text { Heat of isomeri- } \\
\text { zation of the gas } \\
H_{i}^{\circ}(\mathrm{g})-H_{n}^{\circ}(\mathrm{g}) \\
\text { at } 25^{\circ} \mathrm{C} \\
\\
\text { kcal/mole } \\
0 \\
-1.68 \pm .023 \\
-1.09 \pm 0.21 \\
-2.58 \pm 0.22 \\
-4.44 \pm 0.21\end{array}$} \\
\hline 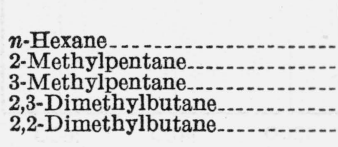 & $\begin{array}{l}\text { kj/mole } \\
0 \\
-5.44 \pm 0.87 \\
-3.16 \pm 0.78 \\
-8.25 \pm 0.83 \\
-14.61 \pm 0.76\end{array}$ & $\begin{array}{l}k c a l / \text { mole } \\
0 \\
-1.30 \pm 0.21 \\
-0.76 \pm 0.19 \\
-1.96 \pm 0.20 \\
-3.49 \pm 0.18\end{array}$ & & \\
\hline
\end{tabular}

a The uncertainty to be assigned to the value for the heat of isomerization of any one of the isomers into any other one is substantially the same as that for the isomerization of $n$-hexane into any one of the other isomers, namely, about $\pm 0.22 \mathrm{kcal} / \mathrm{mole}$ for the gas at $25^{\circ} \mathrm{C}$. 


\section{DATA OF PREVIOUS INVESTIGATIONS}

The heats of combustion of only two of the five isomers of hexane have ever before been measured. Data on $n$-hexane were reported by Stohmann, Kleber, and Langbein [36] in 1891, by Zubow [37] in 1898 , and by Jessup [30] in 1937, and on 2,3-dimethylbutane by Thomsen [38] in 1886. Since no one investigator measured both isomers, and since the older work of Stohmann et al., Zubow, and Thomsen carries uncertainties as large as several kilocalories per mole, any values deduced from these data for the heat of isomerization of $n$-hexane into 2,3-dimethylbutane would have uncertainties as large as, or larger than, the heat of isomerization itself. For example, the data of Thomsen's seven experiments on 2,3-dimethylbutane yield a value for its heat of combustion having an uncertainty [6] of about $2.5 \mathrm{kcal} / \mathrm{mole}$, whereas the entire value of the heat of isomerization itself as determined in the present investigation is $2.58 \pm 0.22 \mathrm{kcal} / \mathrm{mole}$ for the gaseous state.

\section{HEATS OF ISOMERIZATION AS A FUNCTION OF THE TEMPERATURE}

Pitzer [39] has calculated, for each of the five hexanes in the ideal gaseous state at $298.16^{\circ}, 600^{\circ}$, and $1,000^{\circ} \mathrm{K}$, values of $H^{\circ}-H_{0}^{\circ}$, the heat content at the given temperature less the heat content at $0^{\circ} \mathrm{K}$

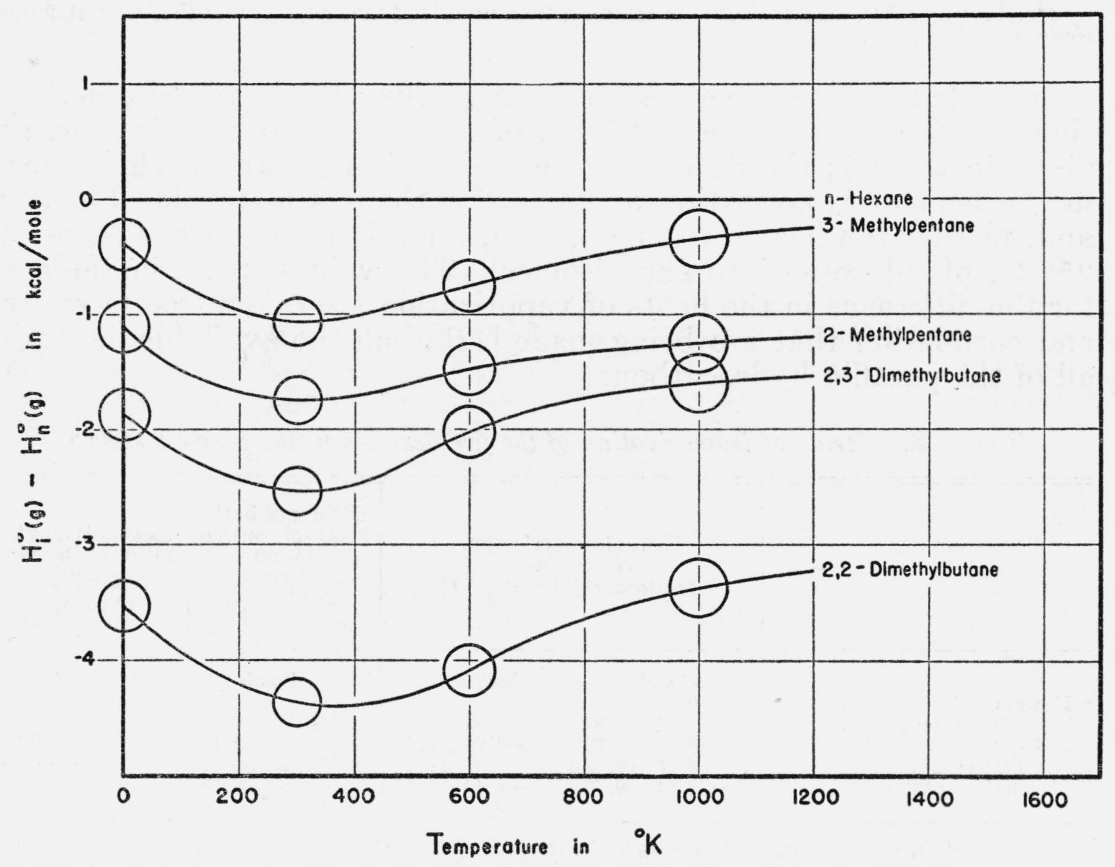

FrgURE 4.- Heats of isomerization of the five hexanes in the gaseous state as a function of the temperature.

The scale of ordinates gives, in $\mathrm{kcal} / \mathrm{mole}$, the value of $\Delta H$ for the isomerization in the gaseous state of $n$-hexane into each of its isomers. The scale of abscissae gives the temperature in ${ }^{\circ} \mathrm{K}$. 
With these values, the heats of isomerization in the gaseous state may be calculated for these temperatures and $0^{\circ} \mathrm{K}$ from the values given for $25^{\circ} \mathrm{C}$ in table 8 . The heats of isomerization so calculated are given in table 9 for $0^{\circ}, 298^{\circ}, 600^{\circ}$, and $1,000^{\circ} \mathrm{K}$, and are presented graphically in figure 4.

TABLE 9.- Heats of isomerization of the five hexanes in the gaseous state at a number of temperatures from $0^{\circ}$ to $1,000^{\circ} \mathrm{K}$

$\left[n-\mathrm{C}_{6} \mathrm{H}_{14}(\mathrm{~g})=i-\mathrm{C}_{6} \mathrm{H}_{14}(\mathrm{~g}) ; \Delta H=H_{i}^{\circ}(\mathrm{g})-H_{n}^{\circ}(\mathrm{g})\right]$

\begin{tabular}{|c|c|c|c|c|}
\hline \multirow{3}{*}{ Substance } & \multicolumn{4}{|c|}{ Temperature in ${ }^{\circ} \mathrm{K}$} \\
\hline & $0^{\circ}$ & $298^{\circ}$ & $600^{\circ}$ & $1,000^{\circ}$ \\
\hline & \multicolumn{4}{|c|}{$H_{i}^{\circ}(\mathrm{g})-H_{n}^{\circ}(\mathrm{g})$} \\
\hline 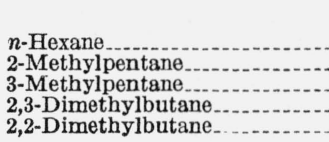 & $\begin{array}{l}\text { kcal/mole } \\
0 \\
-1.04 \pm 0.25 \\
-0.42 \pm 0.23 \\
-1.89 \pm 0.24 \\
-3.60 \pm 0.23\end{array}$ & $\begin{array}{l}k c a l / m o l e \\
0 \\
-1.68 \pm 0.23 \\
-1.09 \pm 0.21 \\
-2.58 \pm 0.22 \\
-4.44 \pm 0.21\end{array}$ & $\begin{array}{l}\text { kcal/mole } \\
0 \\
-1.40 \pm 0.25 \\
-0.78 \pm 0.23 \\
-2.05 \pm 0.24 \\
-4.16 \pm 0.23\end{array}$ & $\begin{array}{l}\text { kcal/mole } \\
0 \\
-1.18 \pm 0.28 \\
-0.36 \pm 0.26 \\
-1.63 \pm 0.27 \\
-3.44 \pm 0.26\end{array}$ \\
\hline
\end{tabular}

\section{DISCUSSION}

Values for the heats of formation of the paraffin hydrocarbons are important for two reasons: (1) they may be combined with values of the free energy function, $\left(F^{\circ}-H_{0}^{\circ}\right) / T$, calculated statistically, to obtain values for the free energies of formation; (2) they may be studied theoretically from the standpoint of the influence of various substituent alkyl groups on the magnitude of the total energy of the molecule and of the energies of the carbon-hydrogen and carbonbonds in these molecules.

Considering the present data on the hexanes in relation to the previously reported data on the butanes and pentanes [4], it appears that values for the heptanes and octanes will be required before a complete analysis can be made of the energies of isomerization of all the paraffin hydrocarbons within the limits of uncertainty of present-day measurements. Such determinations on the heptanes $[40,41]$ and the octanes [40] are now being made.

From the values presented in table 9, it may be seen that with regard to the energy content at $0^{\circ} \mathrm{K}$, for the gas having no translational, no rotational, and only the zero-point vibrational energy, the isomers arrange themselves in order of increasing stability, as follows: $n$-hexane, 3-methylpentane, 2-methylpentane, 2,3-dimethylbutane, and 2,2-dimethylbutane.

\section{REFERENCES}

[1] F. D. Rossini, BS J. Research: (a) 6, 37 (1931) RP260; (b) 7, 329 (1931) RP343; (c) 12, 735 (1934) RP686; J. Research NBS; (d) 13, 21 (1934) RP692; (e) 15, 357 (1935) RP833.

[2] J. W. Knowlton and F. D. Rossini, J. Research NBS 22, 415 (1939) RP1193.

[3] E. J. R. Prosen and F. D. Rossini, J. Am. Chem. Soc. 62, 2250 (1940).

[4] F. D. Rossini, Chem. Rev. 27, 1 (1940).

[5] G. P. Baxter, M. Guichard, O. Hönigschmid, and R. Whytlaw-Gray, J. Am. Chem. Soc. 63, 845 (1941). 
[6] F. D. Rossini and W. E. Deming, J. Wash. Acad. Sci. 29, 416 (1939).

[7] J. R. Eckman and F. D. Rossini, BS J. Research 3, 597 (1929) RP111.

[8] H. C. Dickinson, Bul. BS 11, 189 (1915) S230.

[9] F. D. Rossini, BS J. Research 9, 679 (1932) RP499.

[10] F. D. Rossini and J. W. Knowlton, J. Research NBS 19, 249 (1937) RP1024.

[11] E. F. Mueller, work not yet published.

[12] H. L. Curtis, C. Moon, and C. M. Sparks, J. Wash. Acad. Sci. 29, 313 (1939).

[13] F. Wenner, J. L. Thomas, I. L. Cooter, and F. R. Kotter, J. Wash. Acad. Sci. \$9, 313 (1939).

[14] H. L. Curtis, C. Moon, and C. M. Sparks, J. Research NBS 16, 1 (1936) RP857; 21, 375 (1938) RP1137.

[15] R. S. Jessup and C. B. Green, J. Research NBS 13, 469 (1934) RP721.

[16] T. W. Richards and H. S. Davis, J. Am. Chem. Soc. 39, 341 (1917).

[17] S. W. Parr, Ind. Eng. Chem. 4, 746 (1912).

[18] P. L. Cramer and M. J. Mulligan, J. Am. Chem. Soc. 58, 373 (1936).

[19] M. Wojciechowski, Proc. Am. Acad. Arts Sci. 73, 361 (1940).

[20] D. R. Stull, J. Am. Chem. Soc. 59, 2726 (1937).

[21] B. J. Mair, BS J. Research 9, 457 (1932) RP482.

[22] J. H. Bruun, M. M. Hicks-Bruun, and W. B. M. Faulconer, J. Am. Chem. Soc. 59, 2355 (1937).

[23] L. Schmerling, B. S. Friedman, and V. N. Ipatieff, J. Am. Chem. Soc. 62, $2446(1940)$.

[24] A. V. Grosse, private communication.

[25] B. J. Mair and J. D. White, J. Research NBS 15, 51 (1935) RP809.

[26] P. H. Dewey and D. R. Harper, 3d, J. Research NBS 21, 457 (1938) RP1139.

[27] R. S. Jessup, J. Research NBS 21, 475 (1938) RP1140.

[28] G. Egloff, Physical Constants of Hydrocarbons, vol. 1 (Reinhold Publishing Corp., New York, N. Y. 1939).

[29] T. W. Richards and F. Barry, J. Am. Chem. Soc. 37, 993 (1915).

[30] R. S. Jessup, J. Research NBS 18, 115 (1937) RP966.

[31] L. Keffler, J. Am. Chem. Soc. 56, 1259 (1934).

[32] L. Keffler, J. Phys. Chem. 39, 277 (1935).

[33] G. E. Moore, M. L. Renquist, and G. S. Parks, J. Am. Chem. Soc. 62, 1505 (1940).

[34] F. D. Rossini, BS J. Research 6, 1 (1931) RP259.

[35] J. R. Eckman and F. D. Rossini, BS J. Research 3, 597 (1929) RP111.

[36] F. Stohmann, C. Kleber, and H. Langbein, J. prakt. Chem. 43, 1 (1891).

[37] P. W. Zubow, J. Russ. Phys. Chem. Soc. 30, 926 (1898).

[38] J. Thomsen, Thermochemische Untersuchungen, vol. 4 (Barth, Leipzig, 1886).

[39] K. S. Pitzer, Chem. Rev. 2\%, 39 (1940).

[40] F. D. Rossini and E. J. R. Prosen, work not yet published.

[41] E. C. Gilbert et al., Oregon State College.

[42] F. D. Rossini, E. J. R. Prosen, and D. D. Wagman, work not yet published

[43] E. W. Washburn, BS J. Research 10, 525 (1933) RP546.

Washington, June 12, 1941. 